VINCZE, ANIKÓ

anvincze@gmail.com

assistant lecturer (University of Szeged, Department of Sociology)

\title{
Digital inequalities by gender and socio-economic status among Hungarian students based on PISA 2015
}

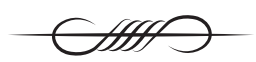

\begin{abstract}
Our paper focuses on the socio-demographic segmentation of dimensions of digital inequalities introduced by DiMaggio and HargitTai (2001). These dimensions include technical apparatus, autonomy of use, ICT skills, social support and purpose of use. We conducted our investigation on the Hungarian subsample of the PISA 2015 dataset, from which we applied variables on ICT use to reveal differences between boys and girls, and by socio-economic and cultural status of students in these dimensions. According to our analysis there are gendered differences as well as differences by socio-economic status regarding dimensions of digital inequalities. Our results can contribute to further research to better understand the relationship between digital inequalities and other dimensions.
\end{abstract}

\section{KEYWORDS}

digital inequalities, socio-economic status, gender, PISA

DOI 10.14232/belv.2020.3.7

https://doi.org/10.14232/belv.2020.3.7

Cikkre való hivatkozás / How to cite this article:

Vincze, Anikó (2020): Digital inequalities by gender and socio-economic status among Hungarian students based on PISA 2015. Belvedere Meridionale vol. 32. no. 3. 86-102. pp 
ISSN 1419-0222 (print)

ISSN 2064-5929 (online, pdf)

(Creative Commons) Nevezd meg! - Így add tovább! 4.0 (CC BY-SA 4.0)

(Creative Commons) Attribution-ShareAlike 4.0 International (CC BY-SA 4.0)

www.belvedere-meridionale.hu

\section{INTRODUCTION}

The use of info-communication technologies is an organic and indispensable part of life for youngsters nowadays. The generation of children who grew up among ICT devices are called by different names like 'Digital Natives' (Prensky 2001), 'Millenials' (Oblinger 2003) or 'Screenagers' (RUSHKof 2006). Scientists dedicated to these generations agree that technology and the digital world has fundamentally changed the lives of these children who have been exposed to ICT actually from their births on. Digital technology affects their personality development, social relationships, values, the way of learning, working and loving. Besides enjoying the benefits of the Internet more and more children and youngsters suffer from its disadvantages and risks. Children and youngsters, who associate the Internet mainly with social media, are often exposed to negative psychological and social effects. These vary from influencing their personality development to being threatened by cybercrime (AIKEN 2020). To map these effects among young people it is important to reveal the characteristics of their ICT use as well as the main factors of segmentation of their usage. In this paper we intend to describe patterns and inequalities of ICT usage along social-demographic characteristics based on the data of the PISA 2015 study.

The use of ICT devices has widely spread and has become a common activity among youngsters in the $21^{\text {st }}$ century. At the beginning, when ICT was new in the society, sociologists focused on the differences between users and non-users. This was the so called digital divide/digital gap concept (NORRIS 2001). However after a rise in the penetration of ICT in society, the focus had to be shifted from the digital gap concept to the digital inequality concept which concentrates on the differences among users (DiMAGGIO et al. 2001, HARGITTAI 2002, 2010). In a previous study (VINCZE 2019) we investigated dimensions of digital inequalities among Hungarian students based on the PISA 2015 database. There we applied the dimensions of digital inequalities introduced by DiMaggio and HargitTai (2001), who distinguished between five aspects to reveal the inequalities among ICT users. These were the following: (1) technical apparatus, (2) autonomy of use, (3) skills and knowledge, (4) social support and (5) purpose of use. We have applied these dimensions to our further analysis. 


\section{DATA AND METHODS}

The analysis of our paper is based on the Hungarian subsample of the Programme for International Student Assessment (PISA) conducted every three years among 15-years old students arranged by the OECD. Besides measuring the competencies of the students all over the world in the field of mathematics, reading and science, the data are supplemented by information on the ICT use of students at home and at school as well. From the beginning on in the year 2000 researchers aimed to catch up with the rising importance of ICT in students' lives. Therefore an additional ICT questionnaire had been developed to reveal patterns of ICT use, and to measure its impact on learning and school performance. The last time this questionnaire was available for the participating countries was in 2015, therefore the analysis is based on these data. We followed the five dimensions of digital inequalities introduced by DiMaggio-Hargittai during our analysis. We adopted some related variables as measures of the dimensions. We examine the dimension of technical apparatus through the access and use of different ICT devices at home. As for the autonomy of use the time spent using the Internet will be investigated. Since the amount of time a student spends on the Internet outside of school reflects to some extent how free or limited the access and the use of the Internet for him or her is. The digital skills can be approached in two ways according to the PISA questions. We can distinguish between skills for a comfortable usage and skills for an independent or proficient usage. To measure both types of skills students had to express to what extent they agree or disagree with ten statements on a four-level scale ${ }^{1}$. As for the dimension of social support we applied variables from the database which showed how typical it is for students to talk about info-communication technologies and to share information about ICT with their friends ${ }^{2}$. Thus social support reflects the level of integration of ICT in the social networks. Finally we revealed the purposes and modes of Internet use among 15-year old student in Hungary. On the one hand general Internet activities and on the other hand modes of Internet use which include school related tasks or support learning have been investigated.

In this paper we aim to reveal the segmentation of dimensions of digital inequalities by socio-demographic factors. We analyse the differences of the dimensions of digital inequalities from two aspects: gender and social background. We examine the variances in ICT use between boys and girls as well as the correspondences between socio-economic background of the students and their ICT use. Socio-economic background is included in the analysis by the ESCS ${ }^{3}$ index. This index consists of three components: (1) the highest level of education of parents, (2) the occupational status of the parents, and (3) the cultural resources at home (number of books), and other educational resources. The ESCS index is a standardized index, which has been computed to have a mean of 0 for all OECD countries and a standard deviation of 1 (OECD 2017). In Hungary the mean of the ESCS index is -0.177 which is lower than the OECD average and a standard deviation of 0.94 which is very close to the standard deviation of the OECD countries.

1=Strongly disagree, $2=$ Disagree, $3=$ Agree, $4=$ Strongly agree

2 Like in case of the previous variable, respondents were able to express the extent of agreement or disagreement on a four-level scale.

3 Economic-Social-cultural Status. 


\begin{tabular}{|l|l|}
\hline $\mathrm{N}$ & 5570 \\
\hline Mean & -0.177 \\
\hline Std. deviation & 0.943751 \\
\hline Minimum & -6.7872 \\
\hline Maximum & 3.0072 \\
\hline
\end{tabular}

1. TABLE: Descriptive statistics on the ESCS index in the Hungarian subsample. Source: PISA 2015, own calculation.

\section{FindingS}

\subsection{Technical apparatus: The use of ICT by gender}

There are some differences between boys and girls in the use of ICT devices at home. The use of a desktop computer is by $20 \%$ higher among boys than girls ${ }^{4}$. Tablets are also more frequently used by boys than girls, the difference however is just 5\% between the two groups ${ }^{5}$. Among girls the rate of laptop or notebook users (by $5 \%)^{6}$ and the rate of cell phone users with Internet connection (by $2.6 \%)^{7}$, is somewhat higher than among boys. However there is no difference between boys and girls in the use of the Internet, they both use it at a high rate ${ }^{8}$.

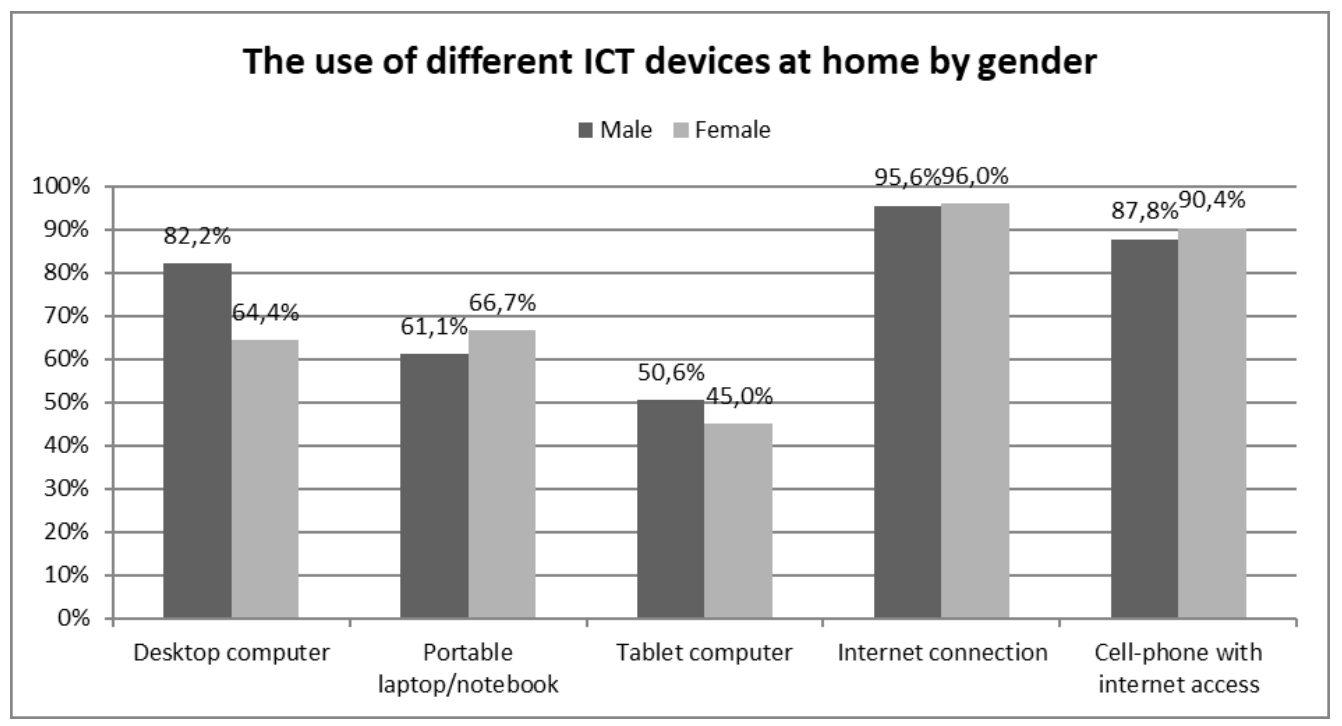

Source: PISA 2015, own calculation

\footnotetext{
Pearson's Chi-square statistic $=219.761 ; \mathrm{p}=0.00$

Pearson's Chi-square statistic $=1.935 ; \mathrm{p}=0.00$

6 Pearson's Chi-square statistic $=25.201 ; \mathrm{p}=0.00$

7 Pearson's Chi-square statistic $=9.285 ; \mathrm{p}=0.01$

8 Pearson's Chi-square statistic $=1.929 ; \mathrm{p}=0.381$
} 
Still relating to the technical apparatus we investigated the difference between boys and girls in the non-use of the available ICT devices in their homes. We found that gender plays a significant role in the non-use of two devices: the desktop computer and the portable laptop/ notebook. One-fifth of the girls don't use the desktop computer although it is available for them in their homes, the same rate of non-users is only $10 \%$ among boys. In the case of laptop we found the opposite relationship: the rate of non-users who have a laptop at home is somewhat higher among boys (15.8\%) than among girls (11.6\%).

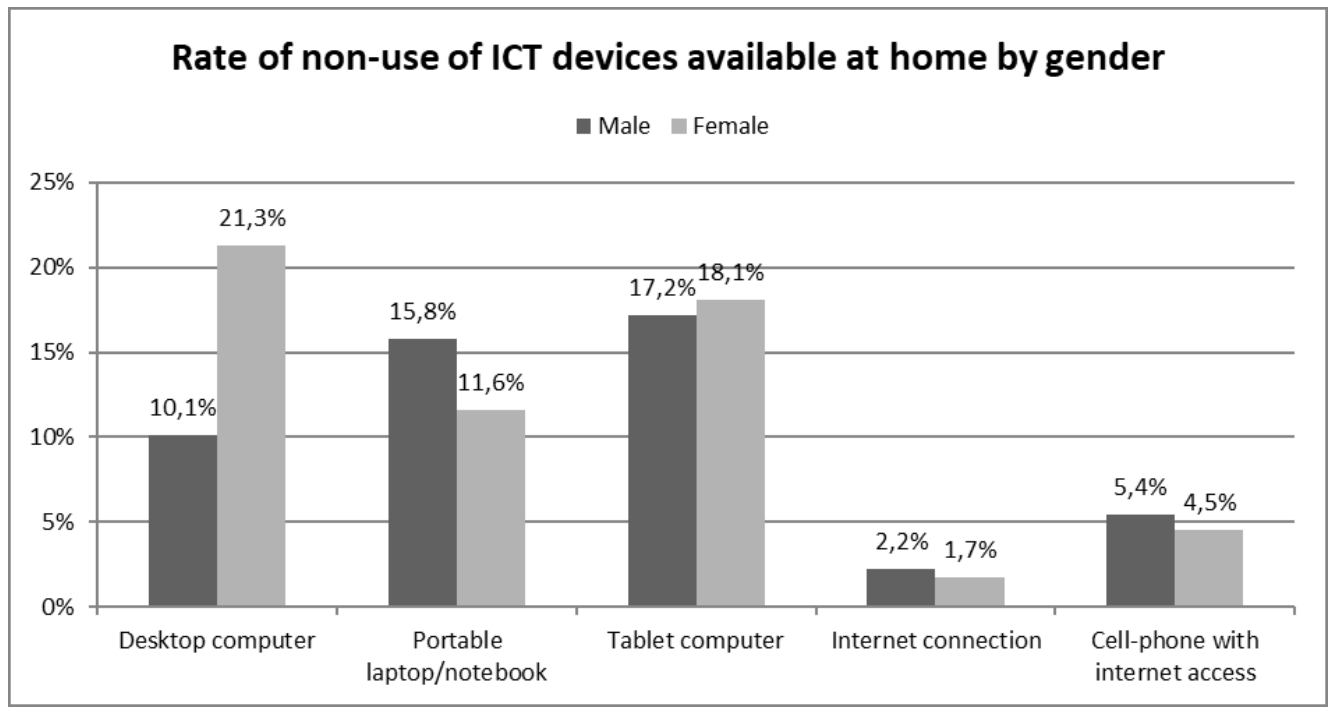

Source: PISA 2015, own calculation

The mean of the number of devices used at home slightly varies between boys and girls. Boys use on average 3.6 devices at home and girls use $3.5^{9}$.

So to sum up, the technical apparatus as a dimension of digital inequalities shows gendered differences. It is more typical for boys to use a desktop computer than for girls. The use of a tablet is also more characteristic for boys, however the difference is not remarkable. More girls use laptops than boys, but the difference is quite low. The data shows no difference between boys and girls regarding the access and use of the Internet and smartphones.

\subsection{Technical apparatus: The use of ICT by ESCS index}

The relationship between the use of different ICT devices and the ESCS index is basically positive. Thus those who have access to ICT devices in their home and use them, have a more favourable social-economic and cultural background than those who don't use ICT devices in their home may it be because they don't have any or for other reasons ${ }^{10}$. Only in case of desktop

\footnotetext{
The independent samples T-test is statistically significant: $t=-3,485 ; p=0,000$

10 All one-way ANOVA tests are statistically significant.
} 
computer use do we see a different correlation. The mean of ESCS index is somewhat lower for those who dispose of a desktop computer and use it than for those who have one in their home but don't use it.

Regarding the different categories of usage the biggest difference between them outlines in case of the Internet. The ESCS index of those who don't have Internet access at home as well as of those who have access but don't use the Internet is much lower than of those who have access and use the Internet.

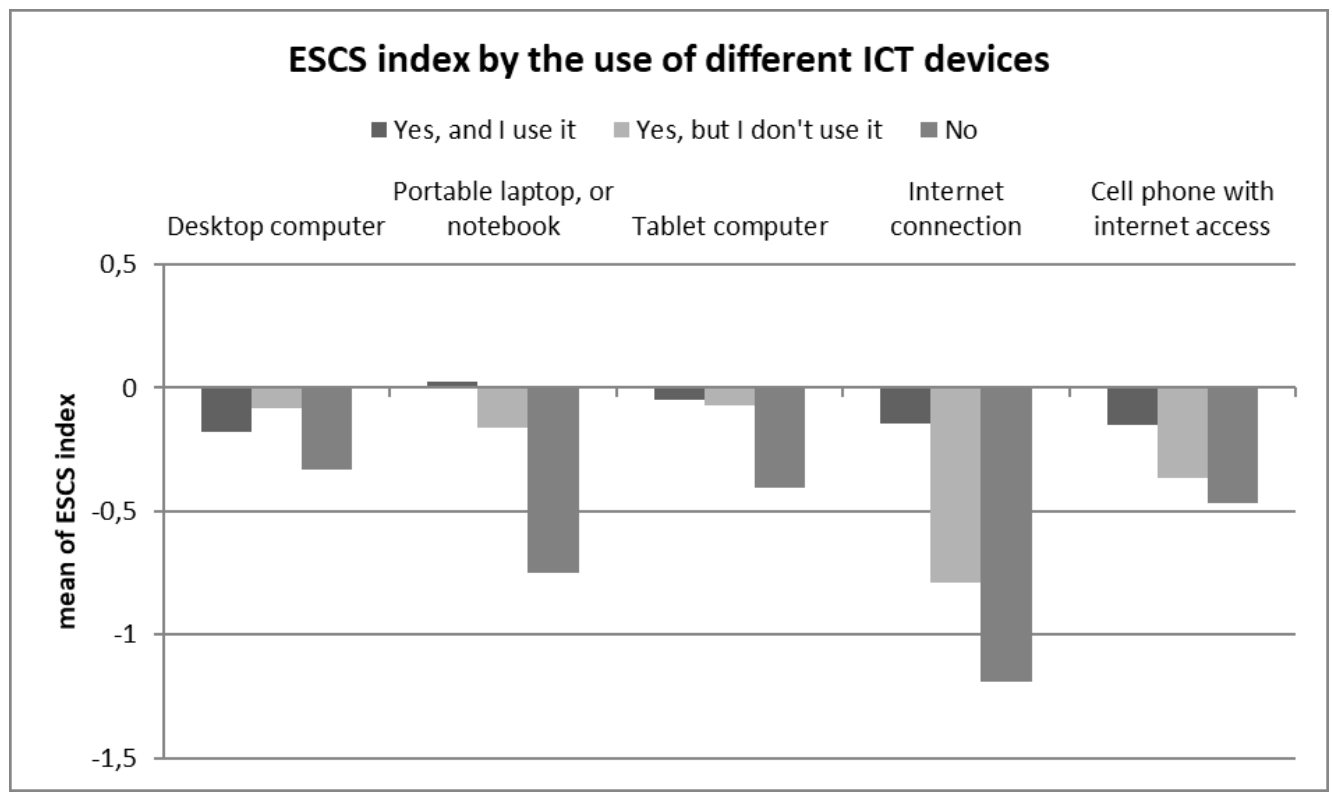

Source: PISA 2015, own calculation

The index to measure the social background showed a positive relationship with the number of ICT devices used at home, the Pearson's correlation coefficient is: 0.211 . Thus the more advantageous the socio-economic background of a student is, the more typical is it for him/her to use more ICT devices at home. According to the linear regression model, when the number of ICT devices used at home increases by one, then the ESCS index rises by $0.273^{11}$.

\subsection{The autonomy of use: The time spent on the Internet by gender}

The PISA data shows no gender differences in the daily time spent online outside of school neither on week days ${ }^{12}$ nor on weekend days ${ }^{13}$.

\footnotetext{
11 The variance explained by the model is $44 \%$. The regression model is statistically significant: $\mathrm{p}=0,000$

12 Pearson's Chi-square statistic $=9.654 ; \mathrm{p}=0.14$

13 Pearson's Chi-square statistic $=10.228 ; \mathrm{p}=0.115$
} 


\subsection{The autonomy of use: The time spent on the Internet by ESCS}

The correlation between the time spent on the Internet and the social status is the shape of an inverted U-curve. It means that both the ones who spend little time online daily and those who use the Internet for more than 6 hours a day have a more disadvantageous social background than those who use the Internet moderately. The ESCS index is the lowest in the case of those students who don't use the Internet at all, neither on week days nor on weekend days outside of school. Among Hungarian students the socio-economic background is the most favourable for those who spend moderate time (i.e. 1-2 hours a day on week days, 2-4 hours on weekend days) online outside of school.

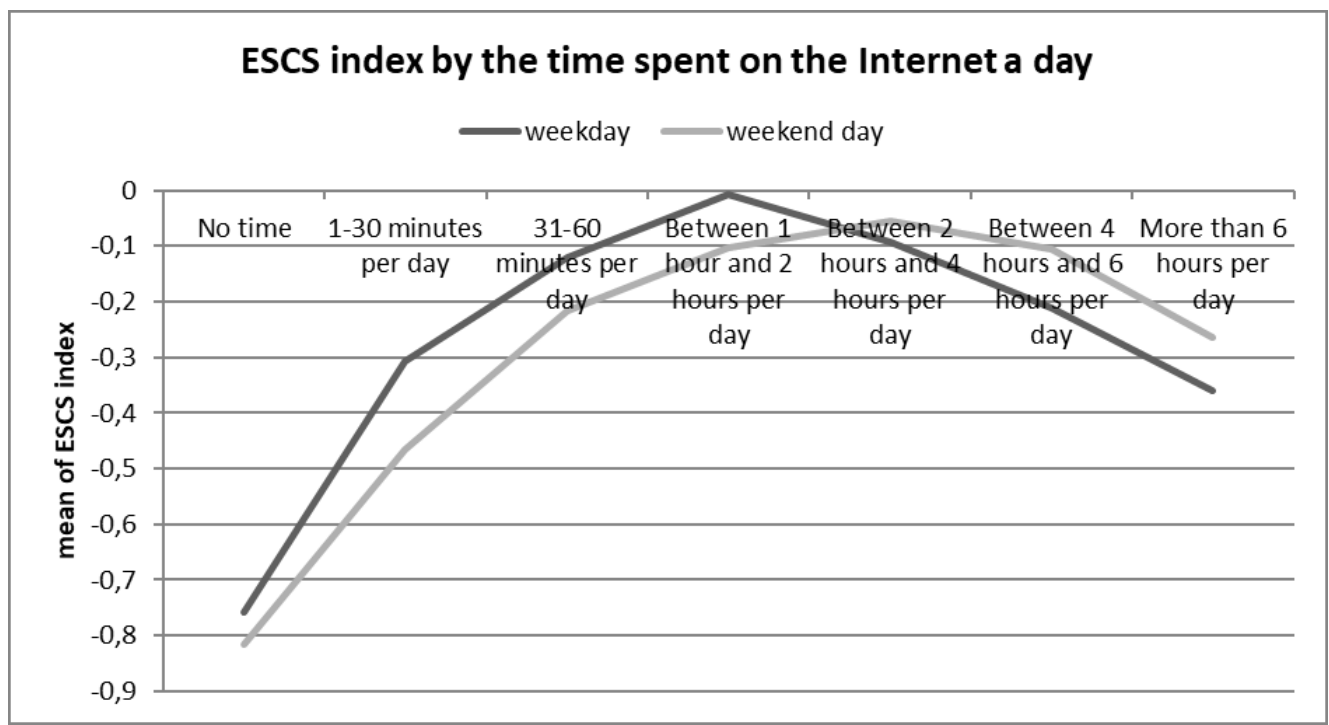

Source: PISA 2015, own calculation

\subsection{ICT skills and knowledge by gender}

In case of both types of ICT skills the analysis reveals that boys feel themselves more confident in the use of ICT. The differences between the self-perceived ICT skills are smaller between boys and girls for general ICT use ${ }^{14}$. However in case of skills for an independent or autonomous use the variation is bigger between boys and girls. Especially when it comes to the installation of new software or the reading about digital devices to be independent the self-perceived skills are much lower for girls than for boys.

14 A higher mean refers to higher level of agreement. 


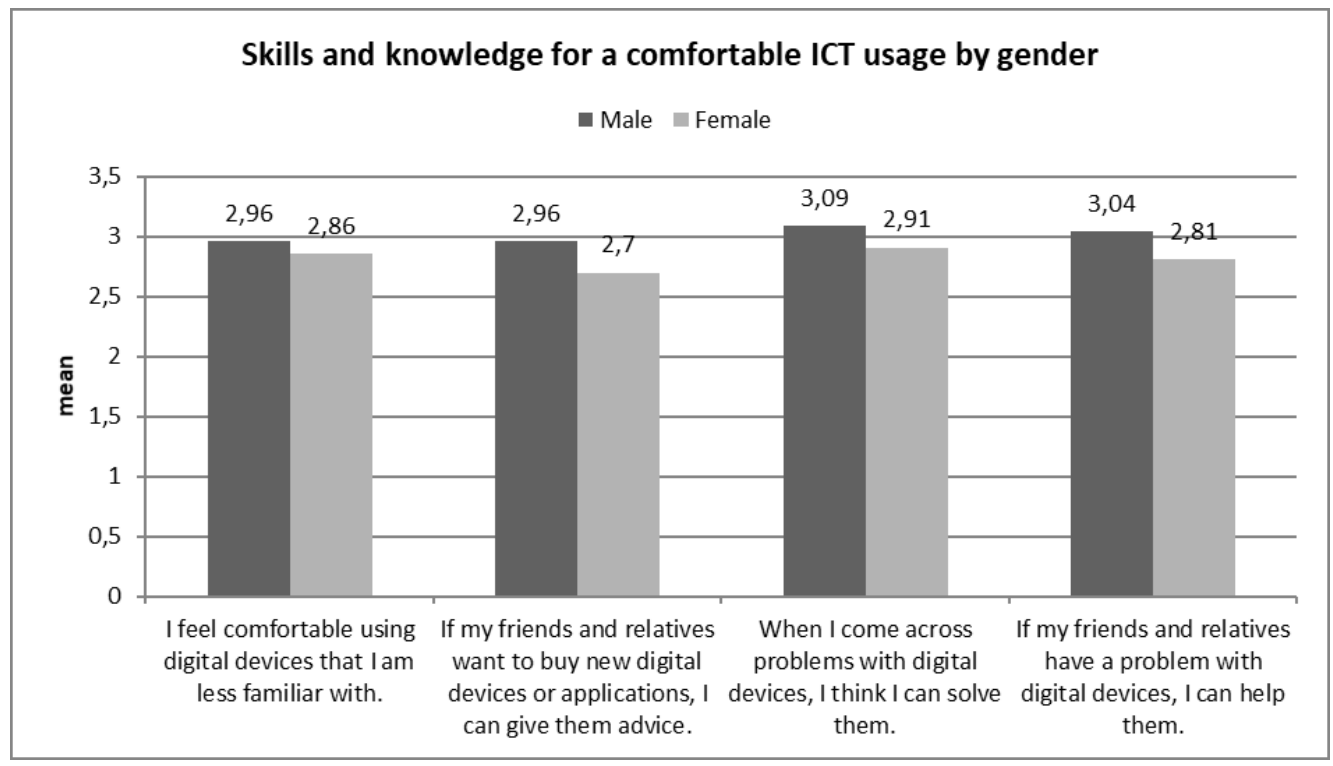

Source: PISA 2015, own calculation

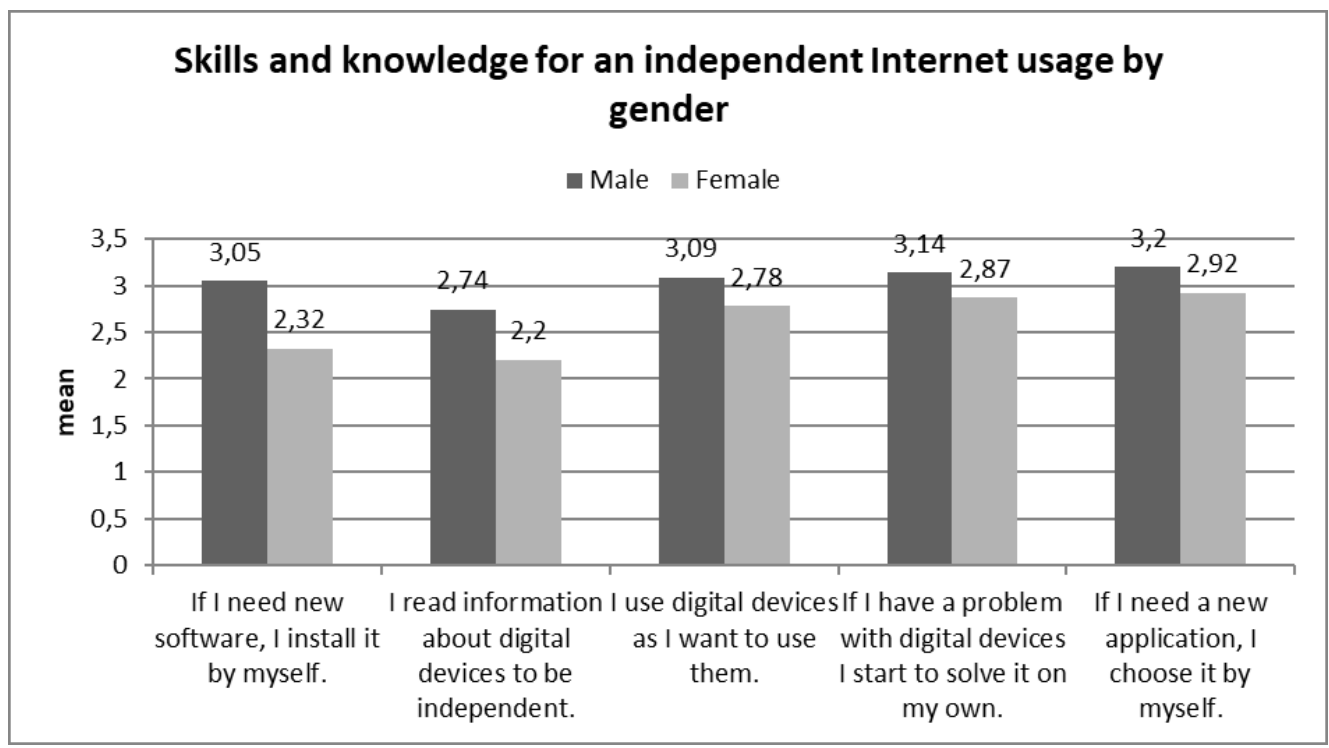

Source: PISA 2015, own calculation

\subsection{ICT skills and knowledge by ESCS index}

The socio-economic background is in connection with the level of self-perceived ICT skills. For both types of skills it reveals that better skills are related to a more favourable socio-economic status. 
The ESCS index is lowest for those students who totally disagree with the statements about ICT skills and knowledge, i.e. whose self-perceived ICT skills are the lowest. We found the lowest ESCS indexes for those students who don't feel comfortable using digital devices they are less familiar with and for those who can't give advice to friends and relatives when they want to buy new devices or applications.

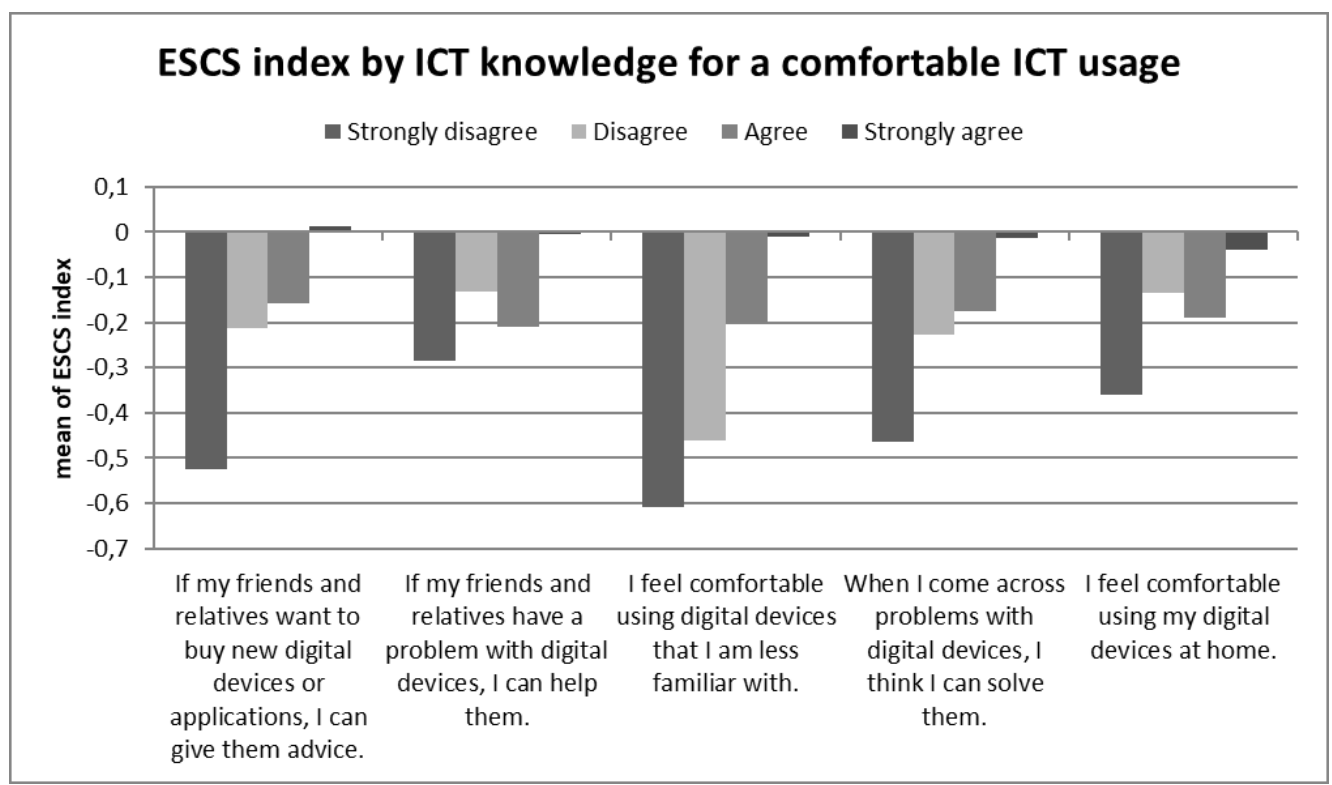

Source: PISA 2015, own calculation

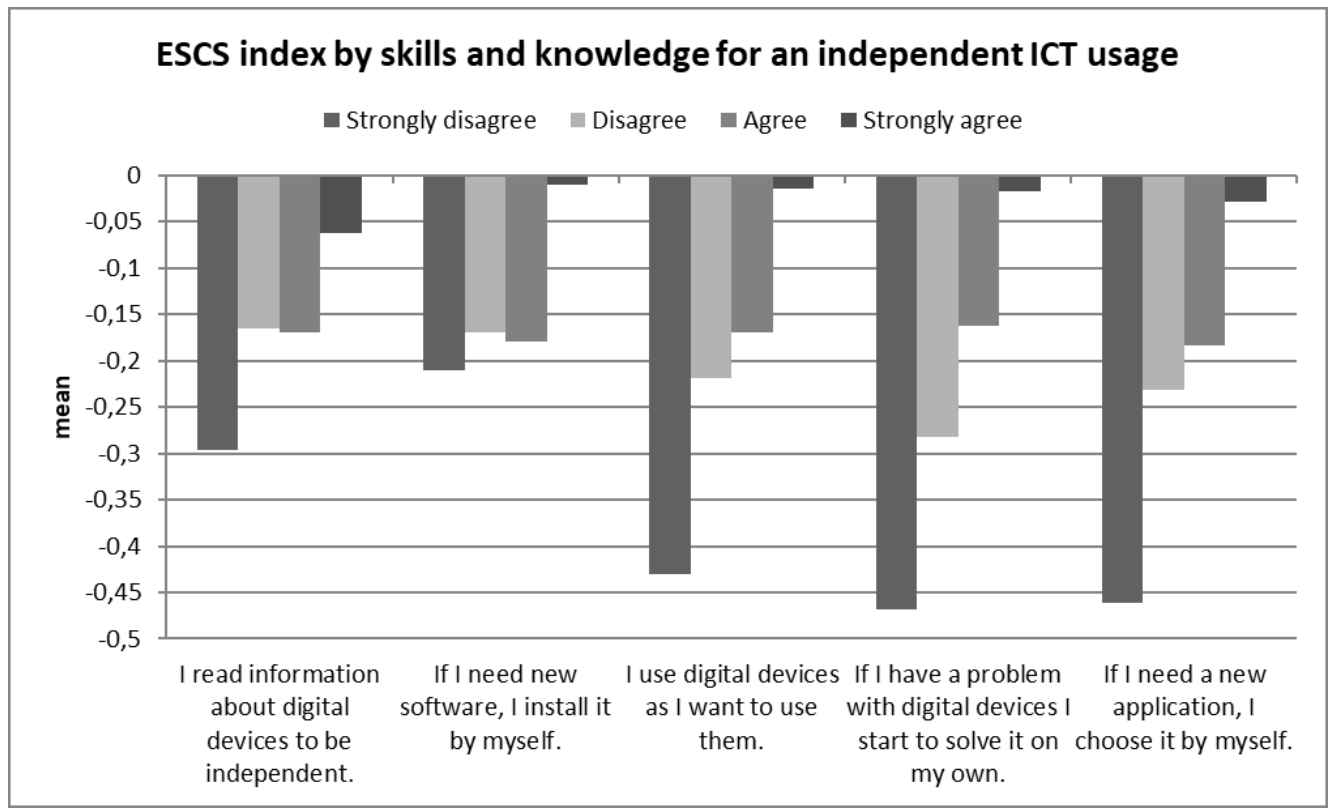

Source: PISA 2015, own calculation 


\subsection{Social support of ICT use by gender}

The use of ICT is rather embedded in the social networks of boys than of girls. The proportion of students agreeing ${ }^{15}$ with the statement that they like to talk about digital devices with their friends is significantly higher among boys (71\%). Furthermore it is also more typical for boys to share information with their friends about digital devices $(66 \%)$.

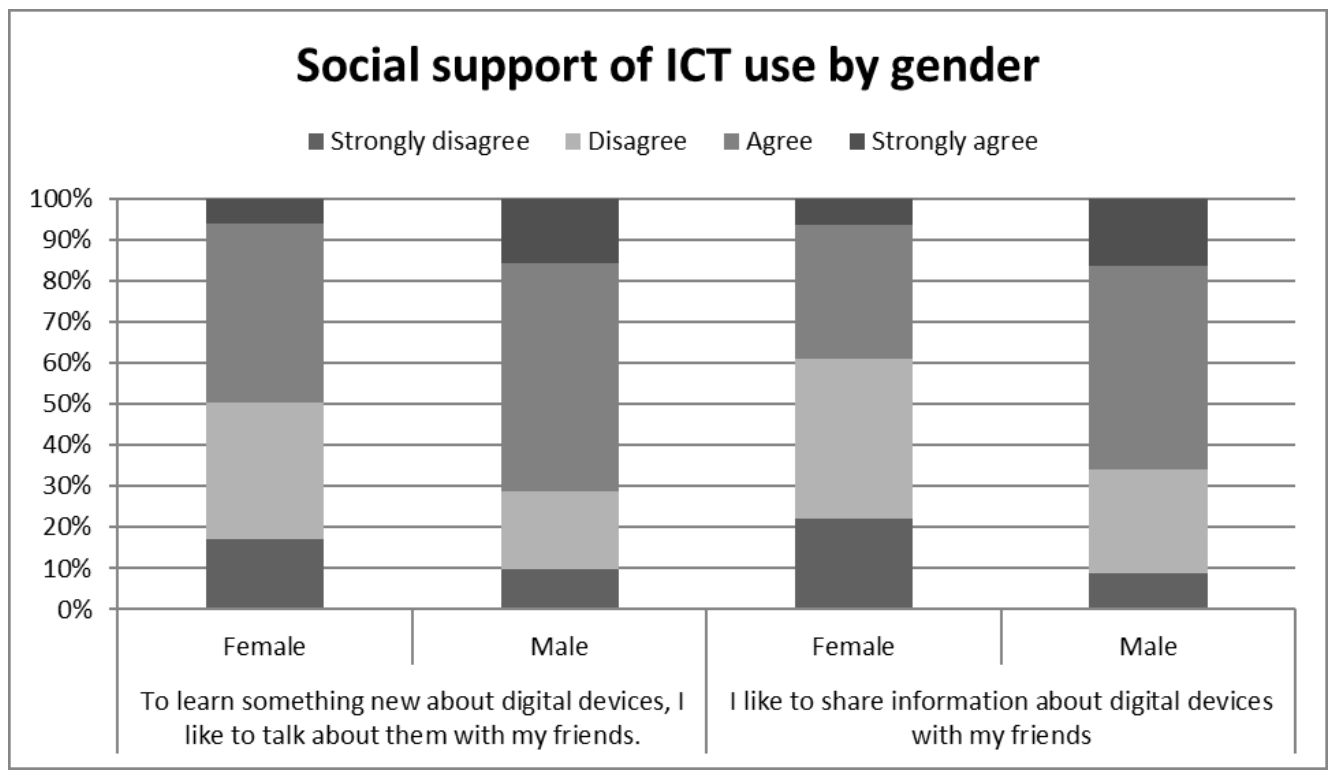

Source: PISA 2015, own calculation

The gendered differences of social support of ICT use might be explained by the distinct interests of girls and boys of that age.

\subsection{Social support of ICT use by ESCS index}

The social support of ICT use measured by the integration of this issue in the social networks, has not revealed a clear tendency for socio-economic status. It seems that social background doesn't influence whether students like to share information about digital devices with friends or whether they like to talk about ICT with them or not.

\subsection{The purpose of ICT use by gender}

The purpose of ICT use has been investigated in the PISA additional ICT questionnaire in two categories. The first one refers to general activities on the Internet - including communication,

15 The categories „Stongly agree” and „Agree” altogether. 
entertainment and looking for information - and the other covers activities related to learning and the studies ${ }^{16}$. We are going to analyse both of these categories separately.

The analysis outlines differences between boys and girls in the frequency of general modes of Internet use. Almost all activities listed are more typical for boys than for girls except for using social networks. In case of two activities we have found almost no differences between boys and girls. These are chatting online ${ }^{17}$ and browsing the Internet for fun videos ${ }^{18}$. The biggest differences in the frequency of use have been found in the case of playing. Boys play one-player games, collaborative games as well as online games on social networks much more frequently than girls ${ }^{19}$.

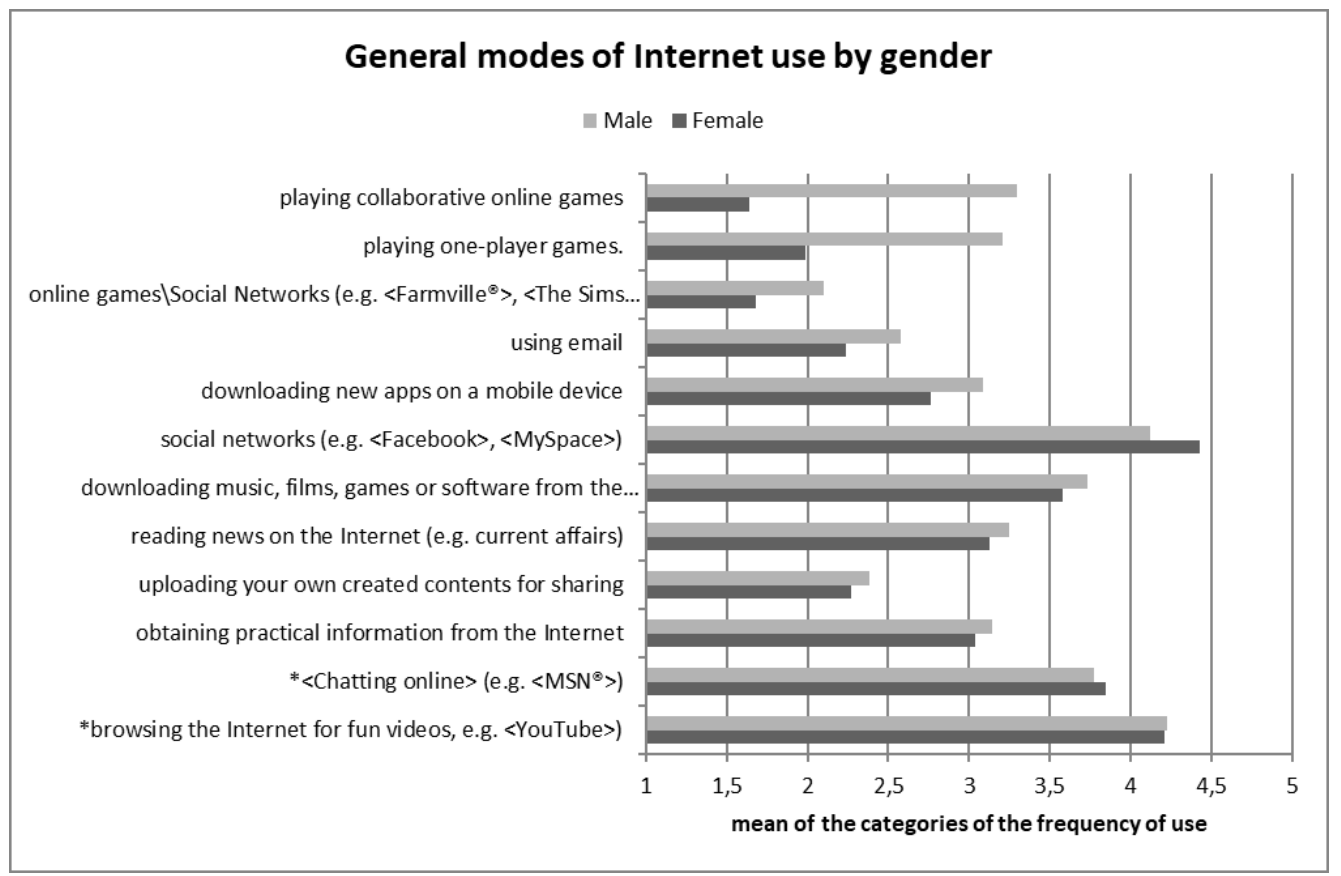

Source: PISA 2015, own calculation ${ }^{20}$.

According to the PISA data it is mostly boys who do activities related to learning and school more often than girls. The difference between boys and girls is the largest in case of downloading learning apps on a mobile device, using e-mail for communication with teacher and downloading/uploading from school's website. There is just one activity that girls do more

16 For all items the frequency of use has been asked on a five-level scale: 1='Never, or hardly ever', 2='Once or twice a month', 3=Once or twice a week, 4='Almost every day', 5='Every day'. A higher mean indicates a higher level of frequency of use.

$17 \mathrm{p}=0.06$

$18 \mathrm{p}=0.533$

19 The mean of the categories of use for females in case of: playing collaborative games online $=1.66$; and of playing one-player games $=1.22$.

20 Items are listed in descending order of the difference (as absolute value) between boys and girls. For items marked with * the difference is not statistically significant $\mathrm{p}>0.05$. 
frequently than boys related to school, namely the use of social networks to communicate with other students about schoolwork. We have found no significant relationship between gender and browsing the Internet for schoolwork ${ }^{21}$.

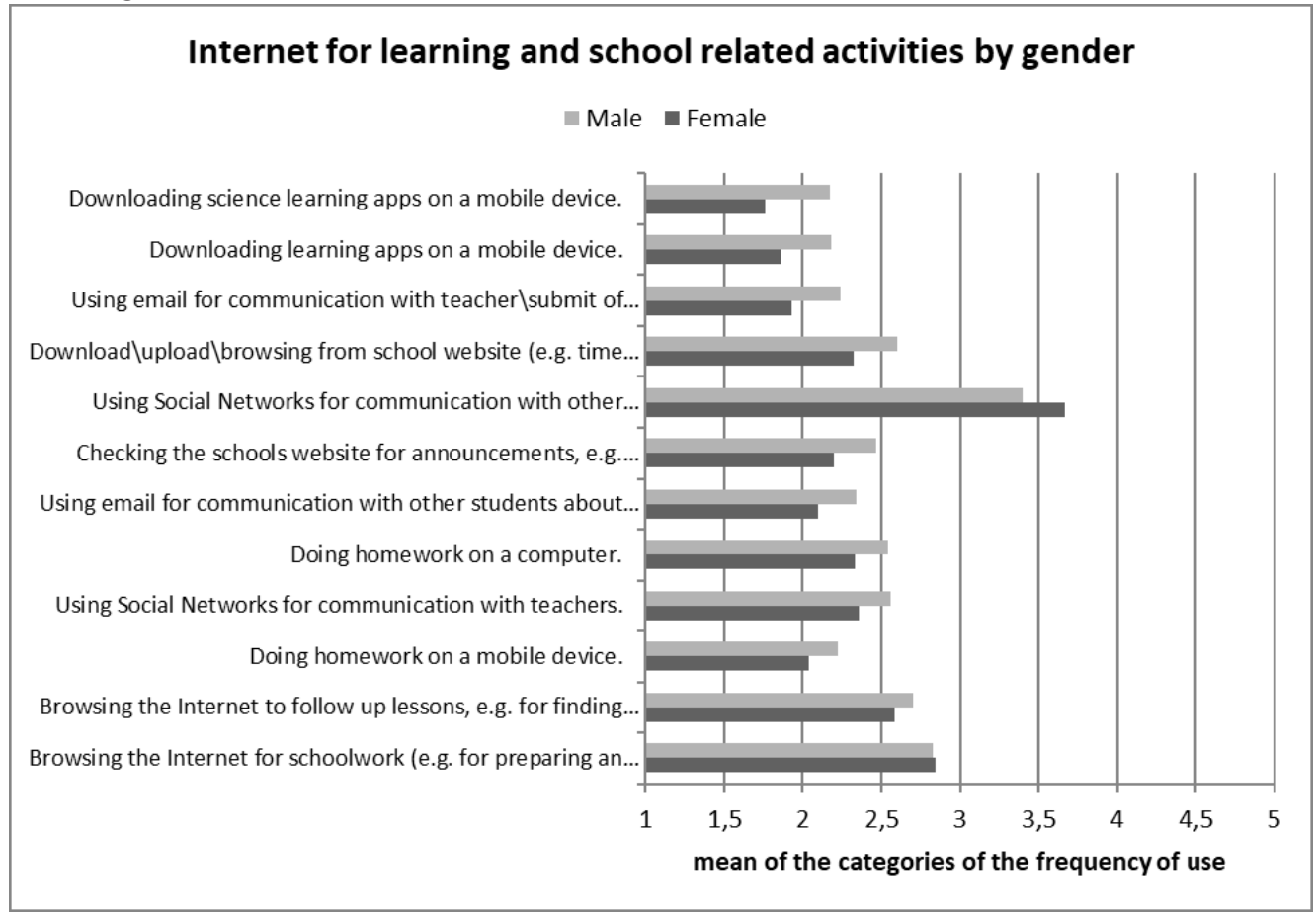

Source: PISA 2015, own calculation

\subsection{The purpose of ICT use by ESCS index}

To analyse the relationship between general modes of Internet use and the socio-economic background we applied principal components based on the Internet activities. Three principal components have been separated ${ }^{22}$. The first (FUN) refers to a frequent use of entertainment and communication activities on the Internet except for playing games. The second one (PLAY) stands for a frequent use of playing games. Finally the third principal component (INFO) shows the frequent use of ICT for obtaining information on the Internet by reading news or searching for practical information. The linear regression analysis revealed a positive effect of the ESCS index on the FUN and INFO principal components. This means that a more favourable socio-economic and cultural status contributes to a more frequent use of the Internet for entertainment and communication, as well as for obtaining information ${ }^{23}$. However the frequent use of the Internet for playing games is not influenced by the ESCS index, the regression model isn't statistically significant.

\footnotetext{
${ }^{21} \mathrm{p}=0.85$

22 The three principal components maintain $75 \%$ of information of all variables.

23 FUN: $\mathrm{B}=0.114 \mathrm{p}=0.00$; INFO: $\mathrm{B}=0.127 \mathrm{p}=0.00 ;$ PLAY: $\mathrm{B}=-0.005 \mathrm{p}=0.731$.
} 
The correlations are more obvious if we compare the means of ESCS index by the different categories of the frequency of use for the items of each principal component. All three items for the FUN principal component show the same tendency: the negative means of ESCS index decrease gradually as the frequency increases. Thus those students, who rarely use social networks, chat online and browse for fun videos on the Internet, have a more disadvantageous socio-economic status then those who engage in these activities on a daily basis.

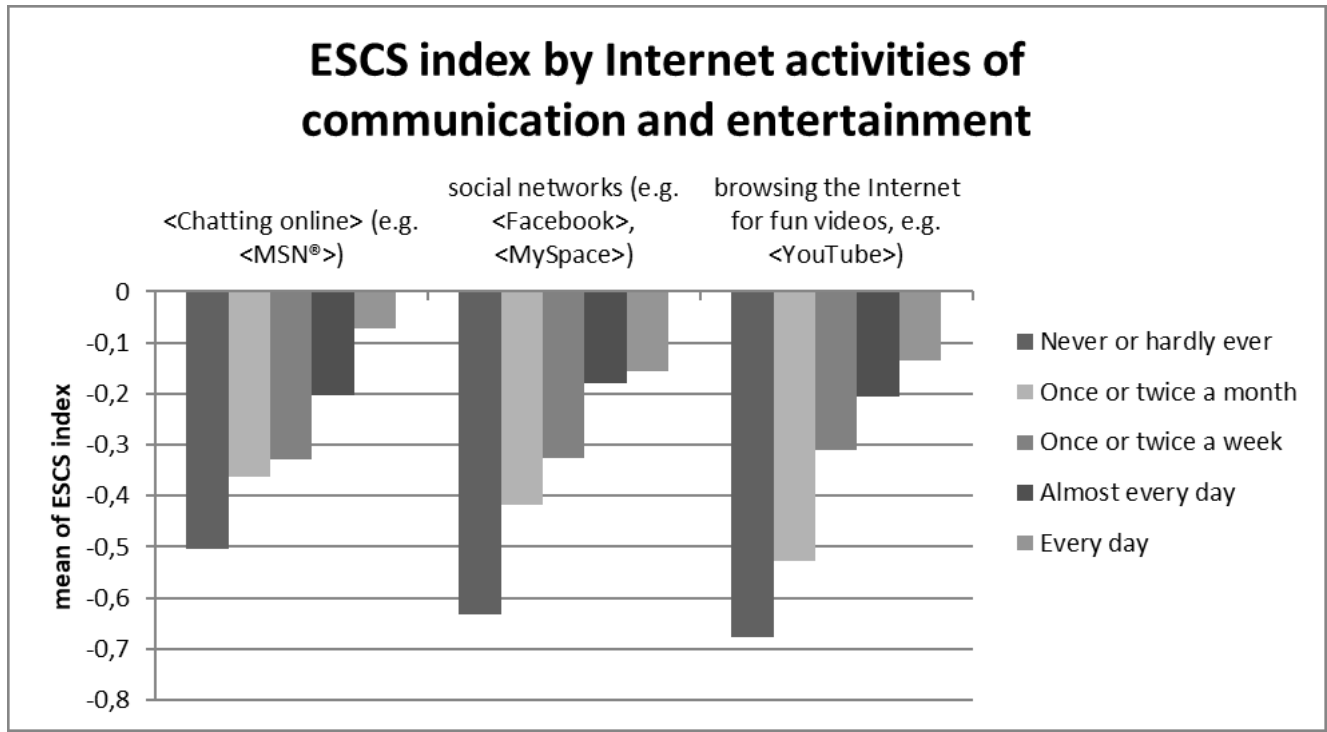

Source: PISA 2015, own calculation

In regard of the items for the INFO principal component we found the same correlation with the socio-economic status but the tendency is not as gradual as in the case of the items of the FUN principal component. Students who never or hardly ever read news on the Internet or obtain practical information have a more disadvantageous social status than those who engage in these activities at least once in a month or a week. 


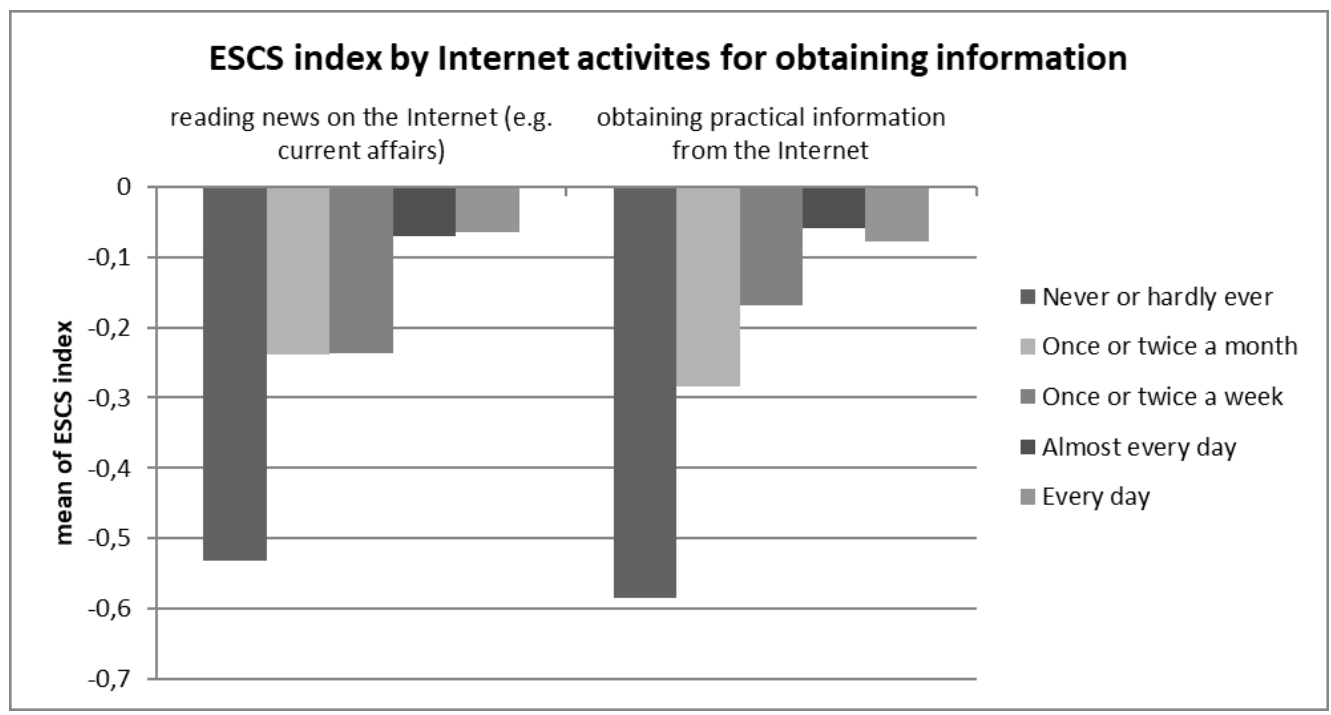

Source: PISA 2015, own calculation

Playing games on the Internet is not related to the socio-economic status, neither are the activities which were excluded from the principal components ${ }^{24}$.

The modes of Internet use linked to learning and school show mixed relationship with the socio-economic and cultural status. For some activities, like doing homework on a mobile device and using social networks to communicate with teachers, the ESCS index is the most favourable for those who never or hardly ever do these activities. An advancing tendency in social status outlines for a lower frequency of some activities, i.e. downloading learning apps, doing homework on a computer or downloading/uploading from school website, however the tendency stops for the less frequent category of use. The mean of ESCS index is remarkably low for those students who never, or hardly ever engage in these activities. Other modes of Internet use for learning however show a different pattern of correlation with socio-economic status. The more frequent a student browses the Internet for schoolwork or to follow up lessons the better his/her socio-economic status is. The tendency is the same for using social networks to communicate with other students about schoolwork. In case of the above activities and doing homework on a computer, the ESCS index of those, who never engage in these activities, is outstandingly low. The socio-economic status according to the frequency of using e-mail for communication with teachers is mixed. 


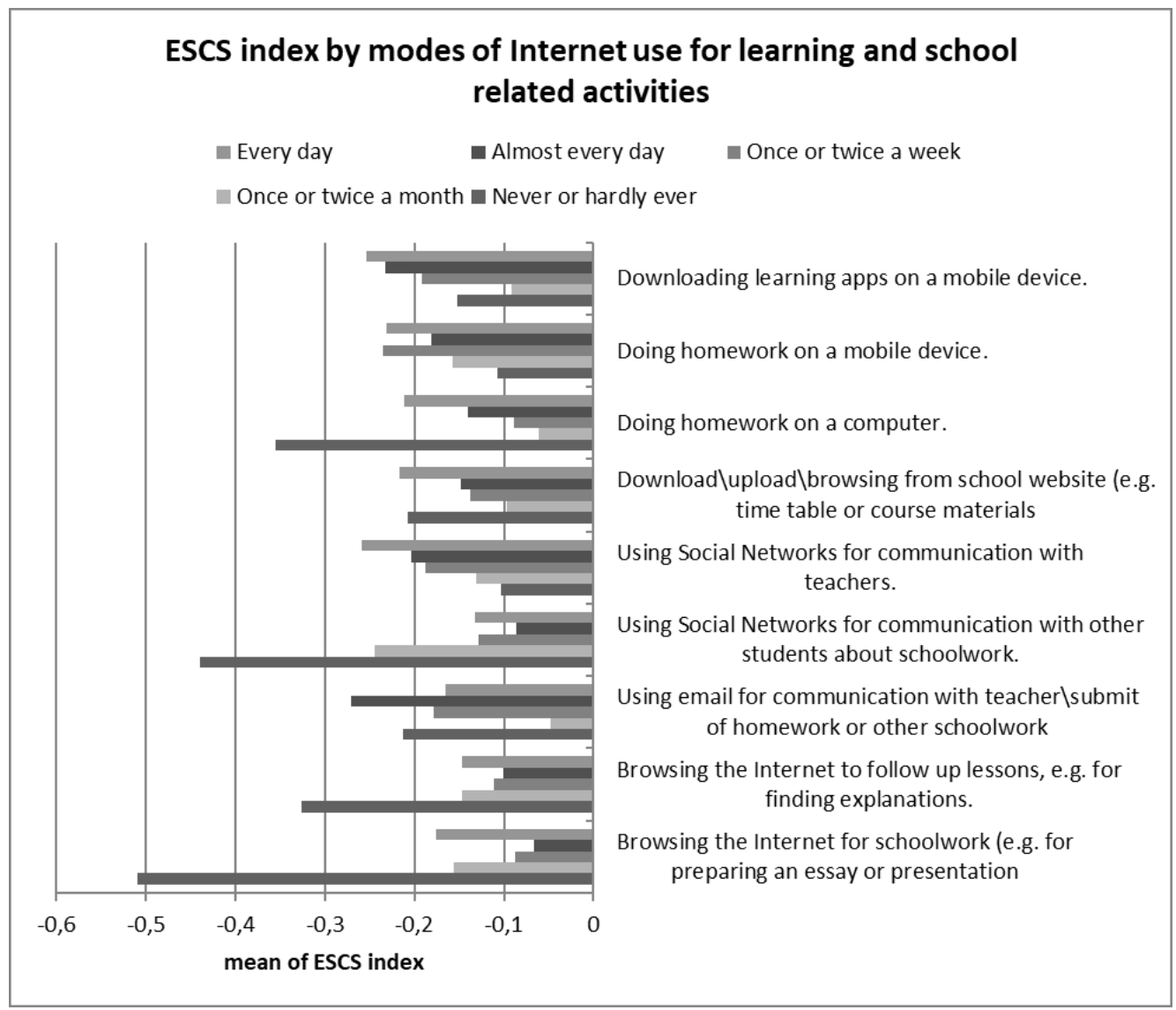

Source: PISA 2015, own calculation

\section{Conclusion}

In our paper we intended to present how different dimensions of digital inequalities are segmented by gender and socio-economic status among Hungarian students. The analysis applied the five digital inequality dimensions defined by DiMaggio and Hargittai. These dimensions cover inequalities among ICT users in regard of the technical apparatus, the autonomy of use, the ICT skills and knowledge, the social support for ICT use and the purpose of use. Our aim was to explore the differences between boys and girls and the variation related to socio-economic and cultural status in these dimensions. The analysis was based on the Hungarian subsample of the PISA 2015 dataset which contains data about many aspects of ICT use of 15-year old students.

In regard to gender we found differences in most dimensions of digital inequalities. In the dimension of technical apparatus it turned out that the use of desktop computer and tablet is more typical for boys, but a higher proportion of girls tend to use a laptop in their homes. The Internet and a cell-phone with Internet access is equally used by boys and girls. As a measure of 
the autonomy of use the daily time spent on the Internet has been investigated. However no gendered differences have been found in this dimension. The social support of ICT use which has been explored by the communication about ICT devices with friends is more typical for boys. So are self-perceived ICT skills, boys feel themselves more confident in using digital devices. In regard of the purpose of ICT use outstandingly differences have been discovered in case of playing computer games online or offline. This activity is most popular among boys. Girls are more engaged in using social networks. For learning and schoolwork the Internet is most frequently used by boys except for using social networks to communicate with other students about schoolwork, this activity is more common among girls.

The socio-economic and cultural background of the students which was measured by the ESCS index, also shows correspondences with the dimensions of digital inequality. In the dimension of technical apparatus, the tendency is quite clear: the access to and the use of any ICT device at home is linked to a favourable socio-economic status. Regarding the time spent on the Internet as a measure of the autonomy of use it reveals that both little time and lot of time spent online daily correlates with a disadvantageous socio-economic background, while a moderate use of 1-2 hours a day on week days and 2-4 hours on weekend days goes together with a favourable socio-economic status. ICT skills outline a clear tendency with ESCS index, the better the self-perceived ICT skills, the higher the means of ESCS index. The dimension of social support doesn't show any clear interpretable correlation with socio-economic status. Finally in the dimension of the purpose of use we distinguished between general modes of use, and the use for learning. As for general Internet use we found that frequent engagement in activities related to communication and entertainment, as well as obtaining information show a positive relationship with socio-economic status. No correlation was found with playing computer games online or offline. In case of Internet use for learning the relationship with socio-economic status is mixed. For most items the socio-economic status is enhanced by less frequent use, i.e. once a month or once a week.

When interpreting results of our analysis it should be kept in mind that tendencies for ICT use change rapidly especially among youngsters. Although the analysis was based on PISA data from 2015, yet it is important to reveal correspondences between dimension of ICT use and socio-demographic factors on these data to provide a benchmark for further analysis. As a further direction of research we aim to continue our investigation by revealing the relationship between digital inequalities and educational inequalities using data on educational performance from the same PISA dataset we conducted the analysis on for this paper.

\section{REFERENCES}

Aiken, M. (2020): Cybercsapda. Budapest, Harmat Kiadó.

DiMaggio, P. et al. (2001): Social implications of the Internet. In Annual Review of Sociology vol. 27. 307-336. https://doi.org/10.1146/annurev.soc.27.1.307

DiMaggio, P. - Hargittai, E. (2001): From unequal Access to Differentiated Use: A Literature Review and agenda for Research on Digital Inequality. http://citeseerx.ist.psu.edu/viewdoc/ download?doi=10.1.1.85.6001\&rep=rep1\&type=pdf 
Hargittai, E. (2002): Second-Level Digital Divide: Differences in People's Online Skills. First Monday vol. 7. no. 4. https://doi.org/10.5210/fm.v7i4.942

HargitTai, E. (2010): Digital Na(t)ives? Variation in Internet Skills and Uses among Members of the "NetGeneration". Sociological Inquiryvol.80. no. 1.92-113.http://www.webuse.org/webuse. org/pdf/Hargittai-DigitalNativesSI2010.pdf; https://doi.org/10.1111/j.1475-682X.2009.00317.x Norris, P. (2001): Digital Divide. Civic Engagement, Information Poverty and the Internet in Democratic Societies. New York, Cambridge University Press.

Oblinger, D (2003): Boomers, Gen-Xers and Millenials: Understanding the new students. Educause Review July/August 2003 http://net.educause.edu/ir/library/pdf/erm0342.pdf

OECD 2017: PISA 2015 Technical Report. OECD Publishing, Paris. https://www.oecd.org/pisa/ data/2015-technical-report/

Prensky, M. (2001): Digital Natives, Digital Immigrants. http://www.marcprensky.com/writing/ prensky\%20-\%20digital\%20natives, \%20digital\%20immigrants\%20-\%20part1.pdf

Rushkof, D. (2006). Screenagers: Lessons in chaos from digital kids. Hampton Press, Incorporated.

Vincze, A. (2019): Dimensions of Digital Inequality Based on Pisa 2015 Data for Hungary. A Study. Belvedere Meridionale vol. 31. no. 4. 163-177. https://doi.org/10.14232/belv.2019.4.12 